\title{
John R. Fowler Jr., Nandkumar M. Rawool: Ultrasons of the hand and ultrasound extremity: a step-by-step guide
}

\author{
Thieme Verlag, New York, Stuttgart, Delhi, Rio de Janeiro, 2017, 202 pp, $178.0 \times 254.0 \mathrm{~mm}$, \\ Hardcover (GEB), e-book, EUR (D) 119,99, EUR (A) 123,40, CHF 138,00, ISBN: 978-1-6262-3688-2
}

\author{
Alain G. Graftiaux ${ }^{1}$ - Pierre Kehr ${ }^{1}$
}

Received: 6 May 2018 / Accepted: 20 May 2018 / Published online: 4 June 2018

(c) Springer-Verlag France SAS, part of Springer Nature 2018

Currently, in the air of time, the practice of echography by the surgeons extends more and more.

This book with the videos associated available on the site with Thieme makes it possible in a very practical way to be familiarized with the basic techniques relating to at the same time the wrist, the elbow, and the shoulder.

The introduction makes it possible to describe the bases of echography, the material, and the various probes.

Each chapter is built same manner with the installation, the positions of the probe, the normal anatomy accompanied by diagrams. The pathological anomalies are described and then the reference marks for the realization of infiltrations. The many photographs show the images of echography making it possible to locate itself well.
Many current pathologies are the object of chapters thus: Fingers have projections, carpal tunnel, tendinitis of Quervain and others, exploration of the wrist, compressions nervous to the elbow, exploration of the biceps. The shoulder is treated in a briefer way with primarily the examination of the shoulder, the nervous infiltrations, and the bursitis.

Any surgeon of the upper limb eager to put himself at echography will find here a help invaluable and particularly well done.

\section{Compliance with ethical standards}

Conflict of interest The authors declare that they have no competing interests.
Pierre Kehr

Strasbourg, France 